(REVIEW ARTICLE)

\title{
The techniques used in tropical and subtropical regions to reduce the negative effects of heat stress on farm animals
}

\author{
Alsaied Alnaimy Habeeb * \\ Biological Applications Department, Radioisotopes Applications Division, Nuclear Research Center, Atomic Energy \\ Authority, Inshas, Cairo, Egypt, P.0.13759.Mobile: 002-01014456768.
}

Publication history: Received on 03 September 2020; revised on 10 September 2020; accepted on 12 September 2020

Article DOI: https://doi.org/10.30574/wjarr.2020.7.3.0337

\begin{abstract}
Good management should aim to well-being, comfort, and maintaining the highly productive and reproductive efficiency of the animals. Under hot climate conditions, the major objective is to facilitate overcoming heat stress, although such criteria are sometimes difficult because of its occasional high costs, altogether with that most countries in which it occurs have severe financial constraints. Providing suitable housing, feeding, disease, and parasite control and heat stress alleviation practices, together with amelioration of the environment, can help heat-stressed animals to express their genetic potentials in tropical and subtropical areas. Although we cannot change the weather, we can modify the animal's environment to minimize heat stress and we can change feeding practices. Some of the management carry out to ameliorate the atmosphere and decrease the animal's heat production and some techniques that can be used to support the animal in dissipating the heat load and to correct the negative effects caused by heat stress. Such techniques are categorized into physical, physiological, and nutritional techniques.
\end{abstract}

Keywords: Animal; Heat stress; Amelioration techniques; Tropical and Subtropical regions

\section{Reduction of the negative effects of heat stress}

Reduction of the negative effects of heat stress can be reduced or even eliminate those losses to improve its productivity has been attempted using different techniques including physiological, physical and nutritional means.

\subsection{First: Physiological techniques}

\subsubsection{Diaphoretics administration}

Diaphoretics substances compounds are used to increase sweat production for increasing the evaporative cooling of the heat-stressed animals. But using these substances increased each of the rectal temperatures and respiration rates [1].

\subsubsection{Diuretics administration}

Diuretics compounds are used to increase water excretion to increase the heat loss by excreting water in urine with the same body temperature and then followed by drinking water which is also of lower temperature than that of the body [2].

\footnotetext{
${ }^{*}$ Corresponding author: Alsaied Alnaimy Habeeb

Biological Applications Department, Radioisotopes Applications Division, Nuclear Research Center, Atomic Energy Authority, Inshas, Cairo, Egypt, P.0.13759.Mobile: 002-01014456768. 


\subsubsection{Goitrogens administration}

Goitrogens compounds block thyroidal iodine uptake and consequently depress thyroid gland activity and consequently the secretion of thyroxin hormone in the heat-stressed animals is reduced to decline heat production. But using these compounds is not favored under heat stress conditions, since the treated animals under such conditions may be affected seriously due to their need to more energy for the greater muscular activity for the high respiratory activity [3].

\subsubsection{Hormonal substances administration}

Supplementation or injection of hormones can be used as a method for the alleviation of heat load on animals since the secretion of most of the hormones is low under heat stress conditions. However, the supplement of thyroxin for this purpose was found to be associated with the increase in the body temperature of the animals [4]. Similarly, insulin injection in the udder was found to show the same effect, besides it increases milk production. Injection by BST also minimized the negative effects of moderately high environmental temperatures on milk yield by increasing heat loss and minimizing the endogenous heat production and related physiological functions without any significant increase in rectal temperature and respiration rates [5]. But these methods need some specific precautions and at the same time are expensive.

\subsection{Second: Physical techniques}

The physical technique includes shading and cooling methods. Any cooling system that is to be effective must be into consideration the intense solar radiation, high ambient temperature, and the typically high daytime relative humidity. These challenging conditions tax the ability of any cooling system to maintain normal body temperature for the animals.

\subsubsection{Reducing ambient air temperature by natural shade}

Trees are an excellent normal source of shade on the grass. Trees are not operative blockers of solar heat but the evaporation of moisture from leaf surface cools the immediate air.

\subsubsection{Reducing ambient air temperature by artificial shade}

Solar radiation is a major factor in heat stress. Obstructive its effects through the use of accurately built shade structures alone increase production strangely. Two options are available: permanent shade structures and portable shade structures [6].

\section{Permanent shade structures}

Major design parameters for permanent shade structures (orientation, floor space, height, ventilation, roof construction, feeding and water facilities, waste management system) depend on climate conditions. In hot and humid climates the alignment of the long-axis in an east-west direction achieves the maximum amount of shade and is the preferred orientation for tied animals, its north to south direction is better where animals are free to move. Space requirements are essentially doubled in a hot climate. Normal air program under the stable shade structure is affected by height and width, the slope of the roof, the size of the edge opening, etc. Painting metal roofs white and adding insulation directly under the roof will reflect and insulate solar radiation and reduce thermal radiation on animals $[7,8]$.

\section{Portable or temporary shades}

Portable shades offer some advantages in their ability to be moved to a new area in different pastures. Portable shade cloth, as well as a light roofing material, may be used on the temporary shades. Shading is one of the most important and cheapest ways to modify the cow's environment during hot weather. It is reported that cows shaded during the dry period gave birth to larger calves and had greater 100-day and 305-day milk yields than un-shaded dry cows. The shed should be placed on a top of a hill if possible, opened on all sides, and with wire or cable fences, the roof should be 3.5 to 4.0 meters high with its long dimension east-west to prevent exposure to high solar radiation. The roof slopes should be south-north to avoid vertical sun heat. The roof can be made of a 10 to $15 \mathrm{~cm}$ layer of hay held in place by wire above and below that realizes insulating and cool effects. Such a roof does not permit penetration of heat from the sun through to radiate into the animals, as well as, little radiant animals are reflected from its underside [9]. Also, hot air under the shade can rise through the loose hay. If solid insulating material or wood shads roofs are used, the top should be painted white or shiny to reflect as much heat as possible and the underside should be dull and dark to avoid reflecting animal heat it receives. The pens should be constructed of wire or cables to offer less resistance to air movement. The adequate surface area from shade per animal is 3.7 - 5.6 square meters for cattle and 1.86-2.79 square meters for sheep to be kept loose in the shed. Vegetation should surround the pens. Shade trees (with falling leaves during winter) should be scattered around and within the yards of the sheds, and such sheds should be scattered in the pasture or range. If 
livestock owners are compelled to build for housing their animals, they have to use insulating materials for the outer walls with adequate ventilation openings and the roofs should erect $60 \mathrm{~cm}$ more than the outer walls to protect the walls from direct sun heat. One of the first steps that should be taken to moderate the stressful effect of a hot climate is to protect the animals from direct and indirect solar radiation. It was estimated that the total heat load could be reduced from 30 to $50 \%$ with a well-designed shade [9].

\subsubsection{Reducing ambient air temperature for cooling the animal by increasing air movement}

Increasing the air movement assistances the evaporation and makes cooling by perspiration more active, and aids removal heat dissipated by animals in the form of radiation, conduction, and convection. It can transfer away moisture in the form of vapor and it also helps in cooling the surroundings (barn walls and roofs, fences, earth, etc.) which in turn helps to keep the animal's cooler. Air conditioning: Air temperature of the micro-environment can be lowered by air conditioning or refrigeration but the expense of such types of air cooling makes these impractical. The air condition technique improves animal productive and reproductive traits of heat-stressed animals. But, it has not practically, because of the high costs of electrical power supply.

\subsubsection{Reducing ambient air temperature for cooling the animal by Fans and Sprinklers}

If you are going to put water on cows, air movement with fans is a necessity. Sprinklers should wet the animal but not the udder. Fans should move enough air to evaporate the water. Sprinklers can be controlled with timers to cycle the water on and off (i.e. 5 minutes on and 10 minutes off in a 15-minute cycle). Fans and sprinklers are usually placed near the feed bunk. The coolest place in the barn should be near the feed bunk to encourage eating. Fans, but not sprinklers, may be placed over free stalls. Fans and sprinklers should also be used in the holding area where temperatures increase rapidly when cattle are concentrated before milking. From another point of view, Habeeb et al. [10] studied the role of niacin and sprinkling in improving milkyield composition and biochemical functions of the heat-stressed Friesian cows. The authors reported sprinkling the heat-stressed lactating cows with tap water caused a significant increase in milk yield (16.7\%), milk protein (6.7\%), and milk fat (6.0\%) contents and a significant decrease in ash content (15.3\%). The increase in daily milk yield, milk composition, and most blood components in the heat-stressed cows due to sprinkling may be attributed to that sprinkling cooled the animal's surface directly by conduction and evaporation (2427 joules dissipated per g water evaporated). The result was reducing the heating load of the summer season by increasing the heat loss through skin vaporization. This reduction in heat load improved the appetite of the animal to increase feed intake and consequently proteins utilization either from feed or from digested rumen microorganisms, are increased. The increase in milk yield and composition may be also due to the role of sprinkling in alleviating the thermal hormonal alterations which depress the milk yield under heat stress, i.e., increase T3 level and decrease cortisol level in sprinkled animals compared with not sprinkled [11]. Consequently, the energy used for cooling processes may be spared for production functions. Moreover, sprinkling aids animals to reach a steady physiological state as indicated by restoration in blood components as well as a reduction in serum transaminases enzyme activities [12].

\subsubsection{Reducing ambient air temperature for cooling the animal by direct evaporative cooling}

Sprinkling uses a large water droplet size to wet the hair coat to the skin. Cooling is accomplished as water evaporates from the hair and skin. Upper body sprinkling followed by forced-air ventilation reduces body temperature; increase feed intake and milk yield. Sprinkling the heat-stressed animals with tap water alleviates the heat stress on respiratory and cardiovascular systems resulting in the significant decreases in respiration and pulse rates [13]. Sprinkling also cooled the animal's surface directly by conduction and evaporation resulting reduction in the rectal temperature of the treated animals as compared to not sprinkled animals. The decrease in rectal temperature, respiration rate, and pulse rate and the increase in hemoglobin and packed cell volume values in the sprinkled animals may be due to increasing the heat loss through skin vaporization and at the same time, alleviating thermal hormonal alterations. The vaporization of $1 \mathrm{ml}$ of water requires 2.43 joules to convert into vapor and this is the amount of heat lost when $1 \mathrm{ml}$ of the sweat evaporates from the skin [14]. The importance of sprinkling in dissipating heat load is due to the high thermal capacity of water $\left(1 \mathrm{cal} . / \mathrm{g} /{ }^{\circ} \mathrm{C}\right)$ and its high heat of evaporation $(580 \mathrm{cal} . / \mathrm{g})$. Sprinkling the animal with water would help in dissipating heat from the skin of the animal through conduction and then evaporation of the water layers coating it [15]. Sprayers in parlor exit lanes also may be used as exit lane sprayers are designed to automatically spray water on the cows as they pass through. The evaporative cooling pad and a fan system that uses the energy of air to evaporate water is a more economically feasible method to cool the micro-environment.

\subsubsection{Reducing ambient air temperature for cooling the animal by fine mist injection apparatus in evaporative cooling systems}

This apparatus injects water under high pressure into a stream of air blown downward from above. Coolers are positioned in the roof of the shade structures or cowsheds and air is pulled through the cooler at very high rates. This 
system is effective in arid climates. High-pressure foggers disperse may be also used. High-pressure foggers disperse is a very fine droplet of water that quickly evaporates, cooling the surrounding air and raising the relative humidity. The typical design incorporates a ring of fogger nozzles attached to the exhaust side of the fan. As fog droplets are emitted they are immediately dispersed into the fan's air stream where they soon evaporate. Animals are cooled as the cooled air is blown over their body and as they inspire the cooled air [16].

\subsubsection{Enhancing the animal's natural mechanism of heat loss}

Cooling in hot and humid climates emphasizes shade, wetting the skin, and moving air to enhance the animal's major mechanism for the dissipation of heat as evaporative cooling from the skin. The internal cooling technique (drinking cool or cold water) acts through the difference between the cool drinking water and warm urine execration temperature which helps in heat dissipation by conduction and also aids in evaporative cooling from the body surface [17, 18]. Conclusively, drinking cool water is a method used to reduce the heat load on farm animals. The importance of the drinking cool water under hot climate may be attributed to the direct effect of the cooling process which aided animals to reach a steady physiological state with respect hemodilution normally occurring in heat-stressed animals. It is also possible that this cooling treatment improved the appetite of animals thus causing an increase in feed intake, especially, protein either from feed or from digested rumen microorganisms and consequently an increase in blood substrates, minerals, and vitamins. It is concluded that drinking cool water is an ideal means and easier technique for improving the productive performance of animals under the summer season [19].

\subsubsection{Reducing the heat load on the animal by drinking cool water}

The advantages of drinking cool water in the decline of the heat load is due to the heat dissipated via conduction as a result of the difference between the drinking cool water and urine temperatures. Moreover, the increase in body water due to the increase in water intake under hot climate helps dissipation of heat by increasing evaporative heat loss through sweating and respiration and by conduction [14]. Drinking cool water is a method used to reduce the heat load on farm animals. The importance of the drinking cool water under hot climate may be attributed to the direct effect of the cooling process which aided animals to reach a steady physiological state with respect hemodilution normally occurring in heat-stressed animals. It is also possible that this cooling treatment improved the appetite of animals thus causing an increase in feed intake, especially, protein either from feed or from digested rumen microorganisms and consequently an increase in blood substrates, minerals, and vitamins. It is concluded that drinking cool water is an ideal mean and easier technique for improving the productive performance of animals under the summer season [18].

\subsubsection{Reducing the heat load on the animal by the shearing process}

The effect of the wool shearing process during the hot summer season on some physiological, nutritional and growth performance was studied by Habeeb et al. [20] and found that shearing lambs during the summer season increased significantly the mean values of DM, OM, CP, CF and NEF digestibility percentages, improved significantly the nutritive values of ration (TDN and DCP), decreased significantly water intake, increased DM intake and body weight gain and improved feed conversion rate. Providing shearing resulted in reducing the adverse effects of heat stress in summer and in turn improved the metabolic media of shorn lambs to increase their productivity. Besides, providing shearing resulted in alleviating the burden of summer heat stress and consequently improved the heat tolerance of lambs raised under semi-arid conditions of the desert and resulted in decreasing the hostile effects of heat stress in summer and turn better the metabolic media of shorn lambs to increase their levels in proteins and thyroid hormones (T4 and T3) [20, 21].

\subsubsection{Reducing the heat load on the animal by increasing water intake}

Water intake will rise by $30 \%$ or more during heat stress. Clean water should be provided to cows where they congregate during the day and while in the holding pen and return alley from the milking parlor. Using wet feeds in the ration or adding water to the ration can also help. Water is one of the most important nutrients required for the maintenance of life and is involved in many physiological functions essential for the maximum performance of farm animals. Water requirements vary and are regulated by many factors such as intake of dry matter, environmental temperature, and loss of water from the body tissues [19]. Livestock needs a plentiful supply of good and clean water for normal rumen fermentation and metabolism, proper flow of feed through the digestive tract, good nutrient absorption, normal blood volume, and tissue requirements. The exposure of animals to elevated ambient temperatures induces an increase in the dissipation of excess body heat, to negate the excessive heat load. The dissipation of excess body heat is excluded by the evaporation of water from the respiratory tract and skin surface via panting and sweating [21]. Drinking cool water under a hot climate may be lead to the direct effect of the cooling process which aided animals to reach a steady physiological state with respect hemodilution normally occurring in heat-stressed animals. It is also possible that this cooling treatment improved the appetite of animals and causing an increase in feed intake, especially, 
protein either from feed or from digested rumen microorganisms and consequently an increase in blood substrates, minerals, and vitamins $[22,23]$.

\subsection{Third: Nutritional techniques}

\subsubsection{Reducing the negative effect of heat stress on the animal by nutritional dietary manipulation}

Heat-stressed animals are required to protein, fat and mineral funds to correct their negative balances since heat stress conditions induce a significant decrease in the DMI and a significant increase in protein and lipids catabolism. Besides heat stress conditions cause an increase in the excretion of urine and sweat containing minerals. Therefore, supplementation with ingredients that include crude protein or NPN (like urea) can be used to correct the negative nitrogen and minerals balance to correct protein and minerals negative balances [24]. Supplementation of heatstressed animals with protein, fat, vitamins, and mineral resources is required to correct their negative balances since heat stress induces a significant decrease in the DMI and a significant increase in excretion of urine and sweat containing minerals [25]. Feeds should be administered during the coolest periods of the day, i.e. in the early morning late in the evening, or by night, under hot climate conditions. In extremely hot days, it is preferred to keep the animals in the sheds. Mineral resources supplementation correct minerals negative balances and consequently improved milk production $[26,27]$. A sharp increase in the secretion of potassium through sweat occurs during hot climate conditions so feeding diets that have a high dietary cation-anion difference improved DMI and milk yield and regulation of acid-base balance [28].

\subsubsection{Reducing the negative effect of heat stress on the animal by ration changes and management}

Rations need to be formulated to compensate for reductions in dry-matter. Lower fiber diets produce less metabolic heat, though care must be taken to ensure adequate fiber is still provided. Additional fat is an option when needing to increase energy while maintaining the necessary fiber. Preserve feed fresh by feeding during early morning hours and in the evening when animals have well appetites. Consider feeding only a third of the ration during the day and two thirds in the evening when temperatures are cooler. Adding a total mixture of ration preservatives will retard feed heating in the bunk. Keep bunks free of spoiled feed to maximize the animal's appetite [11, 12 and 17].

\subsubsection{Reducing the negative effect of heat stress on the animal by supplementary of medicinal plants to the animal diet}

The antioxidant activity is high in medicinal plants and antioxidants play an important role in inhibiting and scavenging radicals that protecting animals against infectious and degenerative diseases [29]. Some medicinal plant extracts and pure forms of active compounds were evaluated for their potential application as modifiers of rumen microbial fermentation to produce VFA which represents the main supply of metabolizable energy for ruminant [30]. Medicinal plant extracts can be used as an antioxidant agent as it inhibited the non-enzymatic peroxidation which may increase immunity and may help the animals to tolerate the heat stress [31]. The antioxidant activity of medicinal plants was due to it acts as a scavenger of oxygen free radicals and protects hemoglobin from oxidation and lowers the production of reactive oxygen species like superoxide anions, $\mathrm{H} 2 \mathrm{O} 2$ and nitrite radical generation [32]. Friesian calves under heat stress condition fed diets supplemented daily with Nigella sativa seeds improved body weight gain [31].

\subsubsection{Reducing the negative effect of heat stress on the animal by the change in time of feeding}

Habeeb et al $[22,23]$ showed that ewes in groups fed at 1200 and $1500 \mathrm{~h}$ were better than ewes fed at $0900 \mathrm{~h}$ in physiological and nutritional aspects. Respiration rate and temperatures of rectal, skin, and ear values decreased significantly while daily feed intake, dry matter intake, and water intake values increased significantly due to late feeding time under summertime. Digestibility of DM, OM, CP, CF, and NFE, as well as TDN and DCP of diet, improved significantly in ewes fed at 1200 and $1500 \mathrm{~h}$ as compared to ewes fed at $0900 \mathrm{~h}$. The same authors concluded that late of feeding time decreased the heat load of the summer season on pregnant ewes and providing feed at $1200 \mathrm{~h}$ or $1500 \mathrm{~h}$ to the animal without adversely affecting performance under hyperthermia. Schwartzkopf-Genswein et al. [33] reported that cattle fed late $(21.00 \mathrm{hr})$ in the day gained marginally more weight than cattle fed in the morning (0900). The lowest ADG was observed for morning fed steers, whereas the highest ADG was recorded for evening fed steers. Cattle fed in the evening also had higher significantly daily dry matter intake than morning fed cattle. These results indicate that it may be beneficial to feed in the evening from a cold climate thermodynamics perspective because the heat produced during fermentation and metabolism is shifted to the evening when cold stress is more likely to occur. Besides, in regions where heat stress is a concern, evening feeding would help decrease any additional heat load that could occur if the animals were fed during the warmest part of the day. Simone [34] suggests that by altering feeding time to the afternoon or evening can help to alleviate heat stress. Heat is generated in the animal by the process of consuming and fermenting feed. Adjusting the time of feeding to late afternoon or evening will mean that additional heat generated from the feed will occur in the cooler hours of the day. Also, multiple feeding can be beneficial during hot weather by 
offering 20 to $40 \%$ of total feed delivery in the morning, and the remainder (60 to $80 \%$ ) in the evening will help to alleviate heat stress.

\section{Conclusion}

Reduce the heat-stressed conditions on animals that can be applied by different techniques. The management practices concerned in hot climate involve modification of the environment, reducing the animal's heat production, and increasing its heat loss. Some techniques that can be used to help the animal in dissipating the heat load and to correct the negative effects caused by heat stress on farm animals in tropical and subtropical countries are classified as physiological, physical, and nutritional techniques.

\section{Compliance with ethical standards}

\section{Acknowledgments}

This work was supported by Biological Application Department, Radioisotopes Applications Division, Nuclear Research Centre, Atomic Energy Authority, Inshas, Cairo, Egypt and all authors decided that no acknowledge any financial interest or benefit we have arising from the direct applications of our research.

\section{Disclosure of conflict of interest}

No any conflict of interest statement in this article.

\section{References}

[1] Marai IFM, Habeeb AAM, Daader AH, Yousef HM. Effects of Egyptian subtropical summer conditions and the heatstress alleviation technique of water spray and a diaphoretic on the growth and physiological functional of Friesian calves. Journal of Arid Environment. 1995; 30: 219-25.

[2] Daader AH, Marai IFM, Habeeb AAM, Yousef HM. Improvement of growth response of Friesian calves under Egyptian subtropical conditions. Internal cooling technique using diuretics and drinking cool water. Proceedings of the 3rd Egyptian-British conference on Animal Fish and Poultry Production, Alexandria University, Alexandria , Egypt. 1989; 2: 595-605.

[3] Kamal TK, Kotby S, El-Fouly HA. Total body solids gain and thyroid activity as influenced by goitrogen, diuretics, sprinkling and air cooling in heat stressed water buffaloes and Friesians. FAO/IAEA Symposium on Isotope Studies on the physiology of Domestic Animals, Athens, Greece, Proceedings Series, IAEA, Vienna. $1972 ; 177-85$.

[4] EL-Masry KM, Habeeb AAM. Thyroid function in lactating Friesian cows and water Buffaloes under winter and summer Egyptian conditions. Proceedings of the 3rd Egyptian-British Conference on Animal Fish and Poultry Production, Alexandria University, Alexandria , Egypt, 1989; 2: 613-20.

[5] Mohamed ME, Johnson HD. Effect of growth hormone on milk Yields and related physiological function of Holstein cows exposed to heat stress. Journal of. Dairy Science. 1985; 58: 1123 - 31.

[6] Shearer JK, Bray DR, Bucklin RA. The management of heat stress in dairy cattle: What we have learned in Florida. Proc. Feed and Nutritional Management Cow College, Virginia Tech. 2005; 60-71.

[7] Yousef HM, Habeeb AAM, Soheir AF, Zahed SM. Effect of direct solar radiation of hot summer season and using two types of sheds on milk yield and composition and some physiological changes in lactating Friesian cows. Proceeding of 7th Scientific Congress, Faculty of Veterinary Medicine, Assiut University, Egypt. 1996; 63-75.

[8] Yousef HM, Habeeb AAM, EL-Kousey H. Body weight gain and some physiological changes in Frisian calves protected with wood or reinforced concrete sheds during hot summer season of Egypt. Egyptian Journal of Animal Production. 1997; 34: 89-101.

[9] El-Sobhy HE. Heat stress in female farm animals: A Review JKAU: Met, Environ and Arid Land Agriculture Science. 2005; 165: 3 - 24.

[10] Habeeb AAM, Aboulnaga AI, Kamal TH. Heat-induced changes in body water concentration, T3, cortisol, glucose and cholesterol levels and their relationships with thermoneutral body weight gain in Friesian calves. Proceeding of the 2nd International Conference on Animal Production \& Health in Semi-Arid Areas, Suez Canal University, Faculty of Environmental Agricultural Sciences, El Arish, North Sinai, Egypt, 2001; 97- 108. 
[11] Habeeb AAM, Gad AE, Teama Fatma EI, EL-Tarabany AA. Means of Alleviation the Negative Effects of Summer Heat Stress on Animals. Journal of Animal Husbandry and Dairy Science. 2018; 2(1): 37-61.

[12] Abdel-Samee AM, Habeeb AAM, Kamal TH, Abdel-Razik MA. The role of urea and mineral mixture supplementation in improving the productivity of heat-stressed Friesian calves in the subtropics. Proceedings of the 3rd Egyptian-British Conference on Animal Fish and Poultry Production, Alexandria University, Alexandria, Egypt. 1989; 2: 637- 41.

[13] Habeeb AAM, El-Tarabany AA, Gad AE, Atta MA. Negative Effects of Heat Stress on Physiological and Immunity Responses of Farm Animals. International Technology and Science Publications (ITS), Agricultural Studies. 2018; 2 (1): 1-18.

[14] Marai IFM, Habeeb AAM, Daader AH, Yousef HM. Effects of diet supplementation and body cooling on heatstressed Friesian calves reared in high ambient temperatures in the eastern desert of Egypt. Tropical Animal \& Health Production. 1997; 4: 201-208.

[15] Habeeb AAM, Marai IFM, Kamal TH. Heat stress, Chapter 2 In Farm Animals and Environment, edited by CJC Philips and D. Piggins, Commonwealth Agriculture Bureau International, Wallingford United Kingdom. 1992; 2747.

[16] Habeeb AAM, Gad AE, Mustafa MM. Improvement of Gain, Feed Efficiency and Physiological Body Functions in Native Bovine Calves during Hot Summer Season using Different Nutritional Supplements. International Journal of Nutritional Sciences. 2018; 3(1): 1021-1028.

[17] Habeeb AAM, Teama Fatma EI, EL-Tarabany AA. Effect of adding selenium and vitamin E to the diet on reproductive traits of female zaraibi goats and growth of their kids. Isotope and Radiation Research. 2012; 44(3): 693-709.

[18] Habeeb AAM, EL-Tarabany AA, Gad AE. Importance of drinking water temperature for heat-stressed pregnant Ossimi ewes during the summer of Egypt. Arab J of Nuclear Sciences and Applications. 2012; 45(1): 223-32.

[19] Habeeb AAM, Gad AE, El-Tarabany AA. Effect of hot climatic conditions with different types of housing on productive efficiency and physiological changes in buffalo calves. Isotope and Radiation Research. 2012; 44(1): 109-26.

[20] Habeeb AAM, Saleh HM, Mustafa MM, Nessim MZ. Effect of a wool shearing process during the hot summer season on the physiological and nutritional performance of Ossimi lambs. Egyptian J Nutrition and Feeds. 2009; 12(3): 391-405.

[21] Bewley JM, Grott MW, Einstein ME, Schutz MM. Impact of intake water temperatures on reticular temperatures of lactating dairy cows. J Dairy Science. 2008; 91(10): 3880-87.

[22] Habeeb AAM, Saleh HM, EL-Tarabany AA, Gad AE, Mostafa MM. Impact of altered feeding time regimen under summertime environmental conditions on the physiological and nutritional performance of pregnant ewes. Isotope and Radiation Research. 2010; 42(4): 1493-1512.

[23] Habeeb AAM, Elwan KM, Marai IFM, EL-Drawany AA, EL-Tarabany AA. Effect of amelioration summer heat stress condition techniques on some blood hormones, vitamins and trace elements in rabbit bucks. Isotope and Radiation Research. 2010; 42(4): 1353-1373.

[24] Habeeb AAM, Marai IFM, Daader AH, Yousef HM. Effects of diet supplementation and body cooling on heat stressed Friesian calves reared under eastern desert of Egypt. Proceedings of 5th Conference on Animal Nutrition, Department of Animal Production and Fisheries, Faculty of Agriculture at Ismailia and Egyptian Society for Nutrition \& Feeds, Suez Canal University, Egypt, 1995; 1: 39-49.

[25] Omnisky K, Kennedy A, Wittenberg K, Mostaghi S. Physiological and production responses to feeding schedule in lactating dairy cows exposed to short-term, moderate heat stress. Journal of Dairy Science. 2002; 85: 730 - 7.

[26] Habeeb AAM, Gad AE, Teama Fatma EI, EL-Tarabany AA.Means of Alleviation the Negative Effects of Summer Heat Stress on Animals. Journal of Animal Husbandry and Dairy Science. 2018; 2(1): 37-61.

[27] Habeeb AAM, El-Darawany AA, Nasr AS, Sharaf AK. Impact of some medicinal plant supplementation on pregnant rabbits diet during the hot summer season. Research Journal of Medicinal Plants. Res J Med Plants. $2019 ; 13$ (4): 145-154.

[28] West JW, Mullinix BG, Sandifer TG. Effects of bovine somatotropin on physiologic responses of lactating Holstein and Jersey cows during hot, humid weather. Journal of Dairy Science. 1991; 74: 840 - 51. 
[29] Anwar UL, Gilani H, Jabeen Q, Khan MAU. A review of medicinal uses and pharmacological activities of Nigella sativa. Pakistan Journal of Biological Science. 2004; 7: 441-51.

[30] Busquet M, Calsamiglia S, Ferret A, Kamel C. Screening for effects of plant extracts and active compounds of plants on dairy cattle rumen microbial fermentation in a continuous culture system. Animal Feed Science and Technology. 2005; 123-124: 597-613.

[31] Awadallah IM. Effect of supplementation with niacin and Nigella Sativa seeds on Friesian calves under heat stress conditions. Journal of Agriculture Science, Mansoura University. 2002; 27(2): 791-801.

[32] Masuda T, Maekawa T, Hidaka K, Bando H, Takeda Y, Yamaguchi H. Chemical studies on antioxidant mechanisms of curcumin: analysis of oxidative coupling products from curcumin and linoleate. Journal of Agriculture and Food Chemistry. 2001; 49: 2539-2547.

[33] Schwartzkopf-Genswein KS, Beauchemin KA, McAllister TA, Gibb DJ, Streeter M, Kennedy AD. Effect of feed delivery fluctuations and feeding time on ruminal acidosis, growth performance and feeding behavior of feedlot cattle. Journal of Animal Science. 2004; 82: 3357-3365.

[34] Simone H. Heat stress in beef cattle, Tech Line, Products and answers that Work, Hubbard Beef Solutions, 2010.

\section{Author's short biography (optional)}

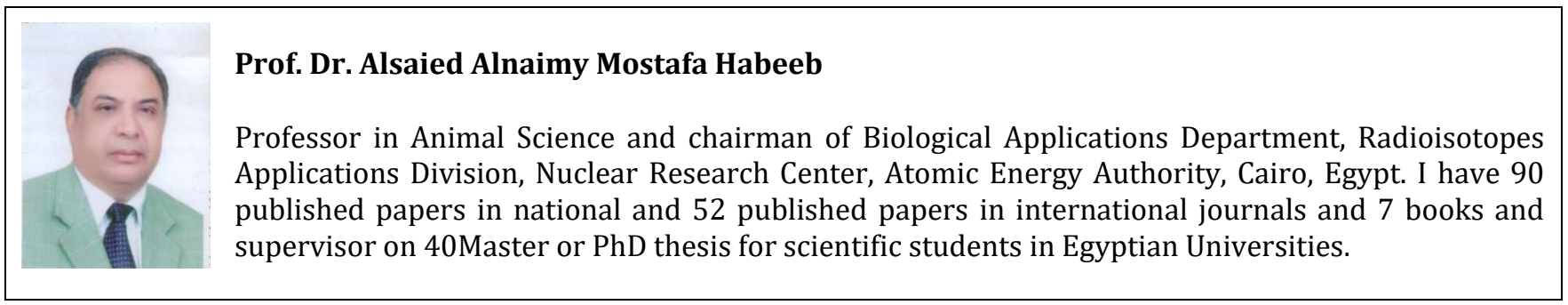

